\title{
Exploring Vulnerability and Interdependency of UK Infrastructure Using Key-Linkages Analysis
}

\author{
Scott Kelly ${ }^{1} \cdot$ Peter Tyler ${ }^{2}$. \\ Douglas Crawford-Brown ${ }^{1}$
}

Published online: 2 September 2015

(C) The Author(s) 2015. This article is published with open access at Springerlink.com

\begin{abstract}
It has been argued the UK has experienced significant underinvestment in critical infrastructure over the last two decades. This in turn has resulted in infrastructure that is less capable of assisting the UK economy to grow. This article seeks to undertake an in-depth analysis of the inter-linkages and economic contributions from infrastructure within the UK. It explores the relationship between nine infrastructure sectors and how these sectors contribute to the rest of the UK economy using keylinkage analysis. Each infrastructure sector is shown to be unique in the way it interacts with other economic sectors and in the form of contribution it makes to the economy overall. Infrastructure is found to be a necessary and important part of economic development. The analysis finds that over the last 23 years there has been a decline in the relative economic contribution from infrastructure to UK GVA. Only two infrastructure sectors increased their relative contribution to GVA since 1992. These were the water transport sector and sewerage and sanitary services sector. Railway transport and gas distribution have had the largest relative decline in contribution towards UK GVA with relative contributions decreasing by over 50 \% since 1992. The three most important infrastructure sectors contributing to UK GDP are land transport, electricity production and distribution and telecommunications respectively.
\end{abstract}

Keywords Input-output analysis · Key-linkages · Infrastructure · Multiplier effects · Interdependencies · United Kingdom

Scott Kelly

sjk64@cam.ac.uk

Peter Tyler

pt23@hermes.cam.ac.uk

Douglas Crawford-Brown

djc77@cam.ac.uk

1 Cambridge Centre for Climate Change Mitigation Research (4CMR), University of Cambridge, Cambridge, UK

2 Department of Land Economy, University of Cambridge, Cambridge, UK 


\section{Introduction}

Physical infrastructure systems are integral to the proper functioning of all modern economies. However, the link between infrastructure availability, economic growth and productivity is still the subject of much uncertainty and debate within the literature (Straub 2008). Although it is clear that infrastructure investment is a crucial factor in economic development it is less clear what forms of infrastructure are most important for different forms of economic activity to occur. There are also concerns, including from the UK Treasury itself, that the United Kingdom is under-investing in critical infrastructure (Bottini et al. 2012).

Infrastructure such as transport systems, water, sanitation services, energy networks and telecommunications represent a large portfolio of public expenditure ranging from one-third to one-half of total public investment for most developed countries (Kessides 1993). Yet, prior to the 1990's infrastructure as an analytic concept was absent from most economic thinking, entering only as a curious but inadequate component of the notion of capital (Prud'Homme 2004). While most formal research studying the relationship between infrastructure and the economy since the 1990's has tended to take a macroeconomic perspective, findings are mixed with some consensus that infrastructure capital has a significant positive effect on economic output and growth (Cain 1997; Démurger 2001; Chakraborty and Nandi 2011; Pradhan and Bagchi 2013). Kessides (1993) suggests the difficulty in designating direct causal links for the economic impact of infrastructure arises because it is hard to attribute any firm conclusions from studies that take such highly aggregated measures attempting to capture all possible externalities and spillover effects that occur as a result of investment in infrastructure.

Unlike market goods where total economic contribution is calculated by taking the quantity of units sold multiplied by unit price, the economic contribution of infrastructure is much more difficult to discern. Complicating matters further is the issue of funding and ownership structures that are becoming increasingly complex. In Fig. 1 the source of funding (public, public/private, private) across different infrastructure types is provided for different infrastructure investments between 2013 and 2014. It is interesting to note the significant contribution being met from the private sector in the provision of several critical infrastructure sectors.

Infrastructure systems are also particularly vulnerable to the effects of disasters. It has been observed that both the frequency and intensity of natural disasters has been increasing, with costs now rising year on year (The Economist 2012; New Scientist 2012). With increasing risks from extreme weather events caused by the onset of

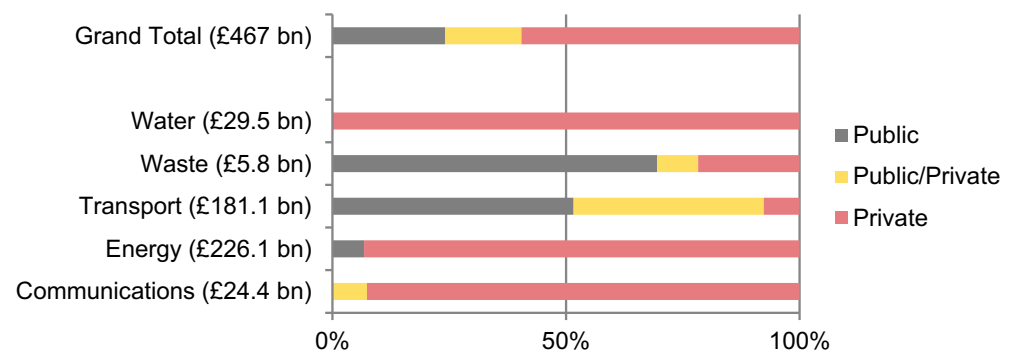

Fig. 1 Future source of funding for different infrastructure categories in the UK. Source: UK National Infrastructure Pipeline (Treasury 2013) 
climate change and a concentration of populations now living in vulnerable coastal cities, river deltas and along earth quake fault-lines, the risks of damage to infrastructure systems is now an acute issue. In the event of a disaster, direct infrastructure failure may have cascading effects on other economic systems (Zhang et al. 2005; Lian et al. 2007). Therefore, understanding the interconnectedness of infrastructure with the rest of economy is critical for assessing the effects of disasters and developing resiliency strategies (Caschili et al. 2015b; Andergassen et al. 2015; O’Kelly 2015).

Key-linkages analysis is a rigorous economic approach that allows the interdependencies between different economic sectors to be quantitatively determined and the wider systemic effects estimated. This article shows how key-linkages analysis can be used to understand the role and purpose of nine independent infrastructure sectors within the UK economy. ${ }^{1}$ It identifies the sectors of the UK economy that are most dependent on infrastructure for the provision of goods and services and estimates the economic contribution that different infrastructure sectors provide to the UK economy when both direct, indirect, employment and income effects are considered together. This research therefore compliments existing multi-layer infrastructure network models (Zhang et al. 2005; Caschili et al. 2015a).

The next section provides an introduction to key-linkages analysis followed by a description of the methods and mathematical derivations used in this paper. The remaining sections describe the data and the results of the analysis. The paper ends with a discussion on the implications of these findings.

\section{Key-Linkages Analysis}

In 2008 the total contribution of infrastructure services to gross value added in current prices across all economic sectors in the United Kingdom was 9.2 \%. ${ }^{2}$ From Fig. 2 it is clear that land transport ${ }^{3}$ has contributed the largest share to gross economic activity followed by telecommunications and then electricity production and distribution. The absolute contribution towards GVA from the services provided by infrastructure increased between 1992 and 2008 (Fig. 2). However, it is more instructive to look at the relative change in contribution from infrastructure services as a percentage of final GVA in each year (Fig. 3). Between 1992 and 2008 the change in overall GVA for the UK economy was $137 \%$, increasing from $£ 547.5$ to $£ 1,295.7$ billion. However, over the same period, the combined sum contribution from all infrastructure services towards GVA decreased. As shown in Fig. 3 the relative contribution from infrastructure services towards GVA has decreased in seven out of nine infrastructure sectors. Only in water transport and sewerage and sanitary services has there been a relative increase in contribution towards GVA compared to 1992. Table 1 shows the percentage change in GVA between 1992 and 2008 for each of the nine infrastructure sectors.

\footnotetext{
${ }^{1}$ The nine infrastructure sectors are: Electricity Production and Distribution, Gas Distribution, Water Supply, Land Transport, Railway Transport, Water Transport, Air Transport, Telecommunications, Sewerage and Sanitary Services.

${ }^{2}$ Using the final demand method the total contribution of infrastructure sectors towards GDP is $8.16 \%$

${ }^{3}$ Land transport includes all commercial land transport activities plus the sale of fuel and motor-vehicle distribution \& repair.
} 


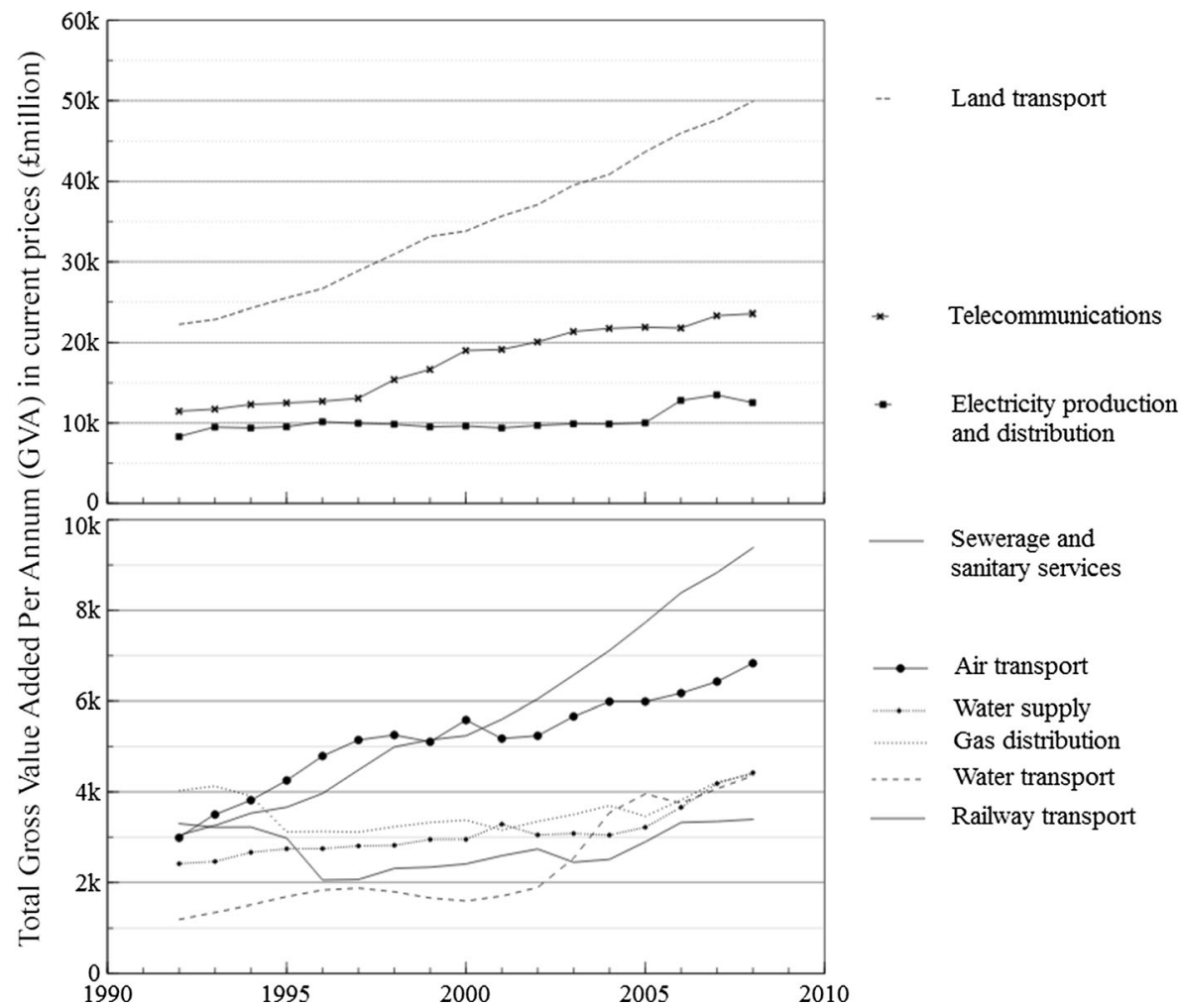

Fig. 2 Total gross value added by infrastructure service type

Information on the size of prominent infrastructure sectors in the UK does not allow us to understand how they relate to other sectors in the economy. Key-linkages analysis can be used to do this. Key-linkage analysis estimates the relative interconnectedness of a sector with the rest of the economy. A sector with a large backward key-linkage

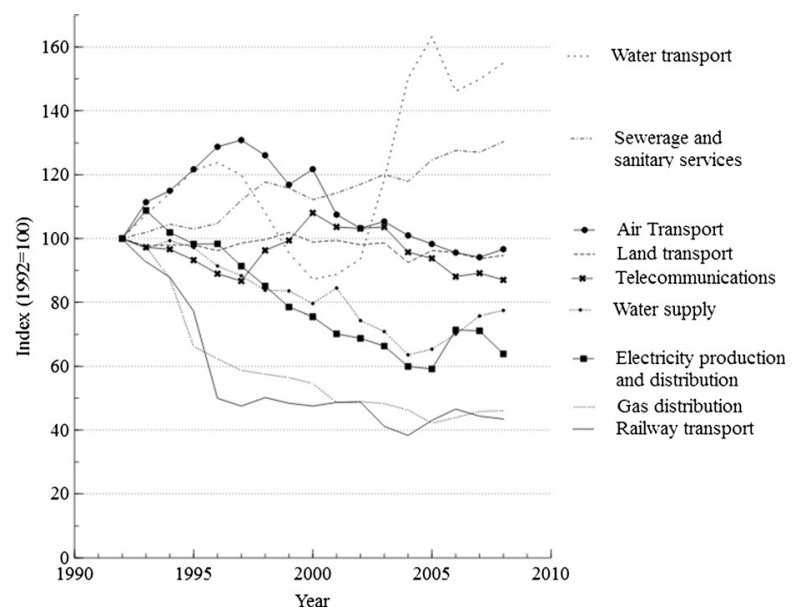

Fig. 3 Change in relative contribution to final GVA. Relative contribution refers to the percentage contribution of value added towards final GVA in any given year 
Table 1 Relative contribution of UK infrastructure to GVA between 1992 and 2008 at basic prices ${ }^{1}$

\begin{tabular}{|c|c|c|c|c|}
\hline \multirow[t]{2}{*}{ Infrastructure sector } & \multicolumn{2}{|c|}{ GVA at basic prices ( $£$ million) } & \multicolumn{2}{|c|}{ GVA as percentage of total GVA for that year } \\
\hline & 1992 & 2008 & 1992 & 2008 \\
\hline Electricity production and distribution & 8,288 & 12,533 & 1.51 & 0.97 \\
\hline Gas distribution & 4,026 & 4,386 & 0.74 & 0.34 \\
\hline Water supply & 2,414 & 4,423 & 0.44 & 0.34 \\
\hline Land transport & 22,261 & 49,887 & 4.07 & 3.85 \\
\hline Railway transport & 3,301 & 3,394 & 0.60 & 0.26 \\
\hline Water transport & 1,188 & 4,357 & 0.22 & 0.34 \\
\hline Air transport & 2,987 & 6,831 & 0.55 & 0.53 \\
\hline Telecommunications & 11,456 & 23,585 & 2.09 & 1.82 \\
\hline Sewerage and sanitary services & 3,040 & 9,379 & 0.56 & 0.72 \\
\hline
\end{tabular}

Nominal basic prices are the amount received by the producer for the purchase of a unit of good or service produced minus any tax payable and plus any subsidy receivable. It excludes transport charges invoiced separately by the producer. Source: (ONS 2012)

metric indicates this sector is heavily reliant on its suppliers for the provision of goods and services. On the other hand a sector with a large forward linkage indicates it relies heavily on other sectors for the sales of goods and services. These indicators were first used to identify key sectors of the economy that may constrain or encourage economic growth (Chenery and Watanabe 1958). Key-linkage metrics are calculated using information contained within input-output tables and therefore are able to provide a robust source of data for identifying the economic structure and importance of both backward and forward linkages between the economic sectors of an economy. The relative size of economic linkages can be used to highlight strengths, weaknesses and vulnerabilities within an economy. Importantly, key linkages analysis helps identify bottlenecks and vulnerabilities in supply chains so that the effects of disruptions can be avoided or minimised through new investment, better reporting and new policy. This is particularly useful for looking at the effects of disasters that may lead to cascading infrastructure failure.

The first practical application using the concept of economic linkages to measure the importance of different relationships amongst economic sectors was proposed by Rasmussen in his $\mathrm{PhD}$ thesis titled "Studies in inter-sectoral relations" (Rasmussen 1956). Although Leontief (1951) presented a framework for measuring the interdependence between economic sectors, the methods described by Rasmussen substantially expanded on Leontief's original approach with a particular focus on the interdependence of prices between economic sectors. Rasmussen's major contribution was to present what he called "summary measures of the inverse matrix" to designate a degree of importance of an individual industry within an economy, as shown by the breadth of that sector's contribution and dependence upon all other sectors in the economy. Rasmussen described the crucial feature of a 'key' industry as its ability to call forth a relatively large increase in the output of other sectors when the final demand for its own products increased, while at the same time its output must expand more than average to meet the final demand on other sectors. Today these concepts are now commonly defined as backward and forward linkages within the economic supply chain. 
Key-linkages analysis was developed in parallel with the advancement of inputoutput methods and can be regarded as an important complement to this area of research (Hirschman 1958; Chenery and Watanabe 1958; Miyazawa 1966). Early pioneers in the field of key-linkage analysis such as Chenery and Watanabe (1958) and Hirschman (1958) established the basic methodology and showed how the method could be used to study the structure of economies and for identifying key-sectors. Their main contribution was to postulate that economic development and structural change proceed through sectors with above-average linkages with other sectors of the economy, acting to accelerate and amplify initially small changes and ultimately affect the whole economy (Lenzen 2003). Several authors have since applied these new methods to explain the constraints and opportunities for growth in developing economies (Hazari 1970; Acharya and Hazari 1971; Diamond 1974; Laumas 1975; Beyers 1976; Bulmer-Thomas 1978; Meller and Marfán 1981; Baer et al. 1987; Clements and Rossi 1991; Sonis and Hewings 1992, 1993; Andreosso-O'Callaghan and Yue 2004). Similar methods have also been applied in the identification of key sectors within developed economies (Dietzenbacher 1992; Lenzen 2003; Los 2004; Robles Teigeiro and Sanjuán Solís 2005; Hanly 2012). More recently key-linkage analysis has been used to study the linkage effects of specific sectors within national economies such as construction, manufacturing, and the marine sector (Stilwell et al. 2000; Alcántara and Padilla 2003; Song et al. 2006; Morrissey and O'Donoghue 2013).

Several other methods using the input-output approach have been developed to study the role of infrastructure under conditions of failure. The inoperability inputoutput model (IIM) has gained a great deal of attention for its ability to describe cascade failure and economic loss (Haimes et al. 2005, 2007; Crowther and Haimes 2010). While the IIM estimates the fraction of each infrastructure sector that will remain inoperable under failure, key-linkages analysis is able to determine the relative importance of infrastructure in the supply-chain. In another related approach Jonkeren et al. (2014) develop a coupled engineering-economic model for Italy looking at infrastructure interdependencies.

This research represents a unique and up-to-date study of the key-linkages between infrastructure services and other key economic sectors in the UK, building on previous work completed by Oosterhaven et al $(2001,2014)$. This work estimates both forward and backward linkages and emphasizes the relevance of using the Ghosh model for estimating forward linkages. This research is particularly relevant within a UK context for understanding the hidden connections and relationships between infrastructure and the wider economy.

\subsection{Backward and Forward Linkages}

At the center of the key-linkage hypothesis is the concept of backward and forward linkage indices as well as direct and indirect effects. Direct backward linkages can be straightforwardly defined as the column sum of the technical coefficient matrix $A_{i j}$ thus representing the direct input requirements of production as a function of total output. On the other hand, total backward linkages - that is direct plus indirect effects are defined as the column sum of the Leontief inverse $L_{i j}$ where $\mathbf{L}=(\mathbf{I}-\mathbf{A})^{-1}$ and represents all input requirements ad infinitum to produce one extra unit of output for sector $j$. While direct effects capture immediate changes to total output caused by adjustments 
occurring in one sector, indirect effects capture changes to total output due to interdependencies that occur through other sectors of the economy in the supply chain.

Direct forward linkages can be defined similarly to direct backward linkages. The key distinction here is that instead of referring to direct input requirements, forward linkages refer to the direct output requirements or sales from sector $j$ directly feeding into other producing sectors of the economy. Total forward linkages - that is direct plus indirect effects - are defined as the total sales or output ad infinitum consumed by other sectors of the economy. Direct and indirect effects can therefore be estimated for both backward and forward linkages within an economy. Figure 4 schematically shows the distinction between backward, forward, direct and indirect effects.

Each sector, $i$, takes its inputs from other sectors in the economy and supplies output (sells) to each other sector in the economy. Trade occurring within each industrial sector is referred to as intra-sectoral trade, while trade occurring between different sectors is referred to as inter-sectoral trade. It is often found that intra-sectoral transactions represent a significant component of value within a sector's value chain. In this analysis intra-sectoral trade values are retained and therefore key-linkage metrics can be used to determine the importance of trade that occurs between economic entities within the same sector. Figure 4 below shows the connections occurring across all sectors of the economy where sector $i=1, \ldots ., n \forall i$ and $n$ is the total number of sectors represented by the input-output table. In this schematic final demand is also shown $f_{(i)}$ and includes the final consumption of goods produced by each sector. While forward linkages capture the transactions from sectors down the supply chain demanding goods and services from sector $i$, backward linkages capture all linkages back up the supply chain that provide goods and services to sector $i$. Dashed arrows in Fig. 4 represent the round by round transactions in an economy ad infinitum. Total output is therefore represented by the sum of the round by round intermediate demand plus final demand.

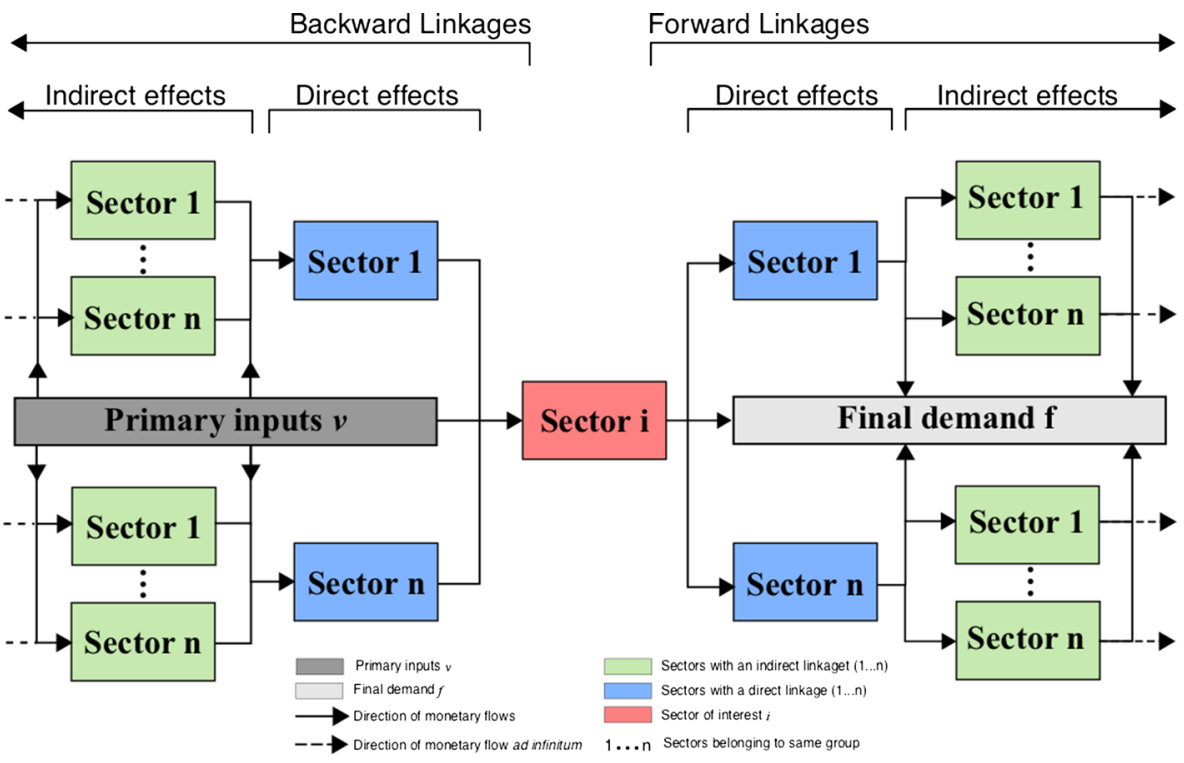

Fig. 4 Backward, forward, indirect and direct effects 


\subsection{Estimation of Economic Linkage Metrics}

As indicated above, analysts differ as to the best approach for measuring linkage effects within an economy. There are several linkage measures that can be employed to measure the importance or 'keyness' of infrastructure service sectors in the UK economy. The following section examines the main approaches. It begins by describing the Rasmussen method and its strengths and weaknesses as a measure of inter-sectoral linkage and for estimating backward, forward, direct and indirect effects within an economy.

\subsubsection{Rassmussen Dispersion Metrics}

The earliest work on linkage measures was completed by Rasmussen where he recommended the use of two linkage measures, these were: the power of dispersion and the sensitivity of dispersion (Hewings 1982) which today are similarly defined as backward and forward linkages, respectively. Let $L_{i j}$ be an element of the Leontief inverse matrix $\mathbf{L}$ and $\mathrm{L}_{\mathrm{i}}$ and $\mathrm{L}_{\mathrm{j}}$ be the $\mathrm{i}$-th row and $\mathrm{j}$-th column of $\mathbf{L}$. If $\mathbf{i}$ is a column vector of ones and 'denotes the transpose, the normalized indices can be developed as follows:

$$
\begin{aligned}
& \text { Power of dispersion : } U_{j}=\frac{\mathbf{i}^{\prime} \mathbf{L}_{j} / n}{\bar{L}}=\frac{\mathbf{i}^{\prime} \mathbf{L}_{j} \cdot \bar{L}}{n} \\
& \text { Sensitivity of dispersion : } U_{i}=\frac{\mathbf{L}_{i} \mathbf{i} / n}{\bar{L}}=\frac{\mathbf{L}_{i} \mathbf{i} \cdot \bar{L}}{n}
\end{aligned}
$$

In Eqs. (1.1) and (1.2) $\bar{L}$ is the average of all elements of the Leontief inverse, where $n$ is the number of sectors in the economy and $U_{i}$ and $U_{j}$ are the Rasmussen indices. When $U_{j}$ or $U_{i}$ it implies that the power of dispersion $U_{j}$ or sensitivity of dispersion $U_{i}$ of the inverse matrix is greater than the average value of the matrix as a whole. Thus one unit change in final demand from a sector where $U_{j}>1$ will generate above average increases in economic activity. On the other hand, for a sector with $U_{i}>1$ it means that when outputs across all sectors increase uniformly, output from sector $i$ will increase above average to meet this new demand. ${ }^{4}$

\subsubsection{Backward and Forward Linkages}

The traditional Leontief forward linkage metric gives an awkward interpretation and led several authors to question the use of the Leontief inverse for estimating forward linkages (Jones 1976). In a standard Leontief framework the sum of all entries in one column for a particular sector $j$ will represent the backward linkage effect in the economy, while the sum of all entries in one row $i$ represents the forward linkage effect in the economy. After further investigation the economic interpretation of a forward linkage in a Leontief based framework is purely hypothetical and does not have a general economic interpretation. For example, the row sum giving a value of 2.0 for the $i$-th industry says that if final demand in

\footnotetext{
${ }^{4}$ Dividing by the correctly weighted average rather than the number of sectors is superior.
} 
each and every industry increases by one unit, then output of the $i$-th industry must increase by 2.0 units to meet this new demand (consisting of 1.0 unit of its own delivery to final demand and 1.0 unit as inputs to other industries). This hypothetical example would never occur in reality, as final demand from each and every sector would never uniformly increase by one unit. ${ }^{5}$ This led to the development of a forward linkage measure based on the elements of the Ghosh model (Miller and Blair 2009). In the Ghosh approach direct forward linkages can be estimated by the row sum (sum of columns) for the $i$-th sector of the output matrix coefficients. This is simply the value of total intermediate sales from sector $i$ as a proportion of $i$ 's total output $x_{i}$. It therefore provides a metric for the increase in goods that must be sold by sector $i$ as result of increased output from itself. Similar to the calculation of the Leontief 'input inverse' derived from the input coefficients matrix, A (Eq. 1.3), the Ghosh 'output inverse' is derived from the output coefficients matrix $\mathbf{B}$ (Eq. 1.4). Each value of the $\mathbf{B}$ matrix therefore represents the output requirements from sector $i$ to sector $j$.

$$
\begin{aligned}
\mathbf{L} & =(\mathbf{I}-\mathbf{A})^{-1} \\
\mathbf{G} & =(\mathbf{I}-\mathbf{B})^{-1}
\end{aligned}
$$

While the input coefficients matrix (technical coefficients matrix) is derived from intermediate inputs as a share of total outputs (including value added) the output coefficient matrix is derived from intermediate sales as a share of total sales (including final demand). The economic interpretation of this new forward linkage measure can be interpreted as follows. The row sum (sum of columns) of the 'output inverse' for the $i$ th sector represents the change in the price of total inputs of all sectors from one unit change in input from sector $i$.

The output inverse was first defined by Ghosh (1958) to represent supply constrained economies and marked the start of a long-running debate which has now been settled (Oosterhaven 1988, 2012; Rose and Allison 1989; Dietzenbacher 1997; De Mesnard 2007, 2009; Guerra and Sancho 2011). Oosterhaven (1988, 1989, 1996, 2012) has conclusively shown that the quantity interpretation of the Ghosh model is nonsensical and only the price interpretation makes theoretical economic sense. Therefore we adopt the price interpretation when calculating forward linkages.

Other contributions and adaptations to the key linkages literature have come from Chenery and Watanabe (1958), Yotopoulos and Nugent (1973), Laumas (1975) and Jones (1976). Direct backward linkages for an economy can be written in matrix form as $B L(d)_{j}=\mathbf{i}^{\prime} \mathbf{A}_{j}$ or in general form as given by Eq. (1.5).

$$
B L(d)_{j}=\sum_{i=1}^{n} a_{i j}
$$

\footnotetext{
5 Jones (1976) criticizes this method using the Korean 'rice' sector as an example where it is shown to deliver less than $14 \%$ of its output directly to intermediate uses but leads to significant expansion of all industries ranking it as the $7^{\text {th }}$ highest Leontief inverse row sum in a 340 sector model. The explanation is that $14 \%$ constituted a large fraction of inputs into a number of small industries which is then enlarged by the equal expansion of all industries. Jones then explains "it is not very enlightening to ask what happens to an industry if all industries, large or small, are to expand by identical unit increments. Jones then proposed that the 'output inverse' (as opposed to the Leontief 'input inverse') is a more meaningful measures of forward linkage.
} 
As the coefficients of the technical input coefficient matrix measure direct effects only, these are known as direct (d) backward linkages. To capture both the direct and indirect linkages of an economy (i.e., total requirements) column sums of the Leontief inverse are used. This is represented in matrix form as $B L(t)_{j}=\mathbf{i}^{\prime} \mathbf{L}_{j}$ or in general form as Eq. (1.6).

$$
B L(t)_{j}=\sum_{i=1}^{n} L_{i j}
$$

There is some disagreement in the literature on whether the on-diagonal elements in A or $\mathbf{L}$ should be included or netted out of the summations. If the purpose of the study is to estimate the Hirschman's input provision (or derived demand effects) then it is normal for the on-diagonal elements to be included. Alternatively if the interest is on the sector's "backward dependence" or linkage with the rest of the economy then they should be omitted. In this analysis the on diagonal elements will be retained as intrasectoral demand can contribute a significant component of a sector's total input or outputs requirements.

As with backward linkages there is also a definition for forward linkages. Following the argument presented above for using the Ghosh model as opposed to the Leontief model for estimating forward linkages, a similar definition can be found for forward linkages (Beyers 1976; Jones 1976; Miller and Blair 1985). In this case direct and total forward linkage effects are defined by Eqs. (1.7) and (1.8) respectively, where $B_{i j}$ represent the elements of the $\mathbf{B}_{i}$ matrix and $G_{i j}$ represent the elements of the Ghosh matrix $\mathbf{G}_{i}$.

$$
\begin{aligned}
& F L(d)_{i}=\sum_{j=1}^{n} B_{i j} \\
& F L(t)_{i}=\sum_{j=1}^{n} B_{i j}
\end{aligned}
$$

In matrix form Eqs. (1.7) and (1.8) are written as $F L(d)_{i}=\mathbf{B i}$ and $F L(t)_{i}=\mathbf{G i}$ respectively. The sum of direct forward and direct backward linkages is defined as total direct linkages (TDL) while total linkages (TL) include both direct and indirect effects for both forward and backward linkages. The backward and forward linkages provided above represent each sector's dependence on each other sector.

Without a frame of reference it is difficult to know whether such links are important when compared to the rest of the economy. Using Rasmussen's framework of normalizing each sector, it is possible to estimate a relative indicator that compares the 'keyness' of each sector when that sector is compared to other sectors of the economy. One limitation of existing key-linkage methods is that they only return a value of 'keyness' as an aggregate indicator for each sector. When looking at 'keyness' it is also necessary to study what sectors are contributing the most or are most important to each sectors 'keyness' within the economy. With knowledge of the relative contribution of each sector to each other sector it is possible to identify the potential for 'dependency risks'. In this research the five most important economic sectors to each infrastructure sector are found and ranked for both backward dependence and forward dependence. 
By studying the structure, size and type of the top five most important economic sectors, a more holistic picture can be provided on the interdependencies, reliance and potential propagation of risks from infrastructure failure to other sectors of the economy. In order to estimate the normalized intersectoral dependence, several new equations were developed for this research. For backward direct and total linkages these values are respectively calculated using Eqs. 1.9 and 1.10, and for forward direct and total linkages these are respectively calculated using Eqs. 1.11 and 1.12.

$$
\begin{aligned}
& \mathbf{B L}(d)_{i j}=\frac{\mathbf{A} n}{i^{\prime} \mathbf{A} i} \\
& \mathbf{B L}(t)_{i j}=\frac{\mathbf{L} n}{i^{\prime} \mathbf{L} i} \\
& \mathbf{F L}(d)_{i j}=\frac{\mathbf{B} n}{i^{\prime} \mathbf{B} i} \\
& \mathbf{F L}(t)_{i j}=\frac{\mathbf{G} n}{i^{\prime} \mathbf{G} i}
\end{aligned}
$$

Each term on the left hand side of Eqs. 1.9, 1.10, 1.11 and 1.12 are square matrices where each element represents the 'normalized keyness' of that sector to each other sector. Summing down the columns for the backward linkages and summing across the rows for the forward linkages produces typical estimates of normalized sectoral keyness. It should be noted that these indicators are not weighted by final demand or total output, and thus a sector with small total contribution may have large linkage with other sectors.

\subsubsection{Coefficient of Variation}

Using the 'keyness' values for each sector it is then possible to rank the relative 'keyness' of different economic sectors to the sector of interest. Thus, the sum linkage measures for each infrastructure sector represent an overall measure of 'keyness' for that sector compared against all other sectors for the economy (i.e., this is the solution of Eqs. 1.7 and 1.8).

Although the method described above allows the calculation of both direct and indirect effects they do not give an indication of the variability of interconnectedness between sectors. It is not only the relative interconnectedness that affects supply chains but also the number of connections held between different sectors of the economy. In other words, sectors that have a large share of their sales coming from a small number of sectors will have different risks than sectors with a number of high key linkages. A solution to the problem of sector variability was proposed by Hazari (1970) by introducing a measure of variance for each sector of the economy, namely: $V_{j}$ and $V_{i}$. Forward linkages are measured through $V_{i}$ while backward linkages are measured through $V_{j}$. A high value of $V_{j}$ can be interpreted as showing that a particular industry draws heavily on only a few sectors (high variance) while a low value of $V_{j}$ can be 
interpreted as a sector drawing relatively evenly from each of the sectors in the economy (low variance). Similarly a high value of $V_{i}$ suggests a particular industry supplies to a few industries while a low value of $V_{i}$ suggests this industry supplies relatively evenly across all sectors. A sector that draws evenly across a greater number of sectors (low $V_{j}$ ) is thought to be more resilient than a sector with concentrated dependence on only a few sectors. Hazari (1970) developed two equations for estimating backward and forward variability linkages. ${ }^{6}$ These equations were improved in this study in several important respects. As already discussed, forward linkages are best calculated using the Ghosh model, so the Ghosh variant of Hazari's equation was derived here. Secondly, Hazari's original approach did not give a relative indicator of variability compared against other sectors. Hazari's equations were therefore updated to provide a relative measure from which sectors could be compared against each other. The newly derived equations to represent relative variability are shown below in Eqs. (1.13) and (1.14).

$$
\begin{aligned}
& V_{j}=\frac{\sqrt{\frac{1}{n-1} \sum_{i=1}^{n}\left(l_{i(j)}-\frac{1}{n} \sum_{i=1}^{n} l_{i(j)}\right)^{2}}}{\sqrt{\frac{1}{n^{2}-1} \sum_{i=1}^{n} \sum_{j=1}^{n}\left(l_{i j}-\frac{1}{n^{2}} \sum_{i=1}^{n} \sum_{j=1}^{n} l_{i j}\right)^{2}}} \quad(i=1, \ldots ., \mathrm{n}) \\
& V_{i}=\frac{\sqrt{\frac{1}{n-1} \sum_{j=1}^{n}\left(g_{(i) j}-\frac{1}{n} \sum_{j=1}^{n} l_{(i) j}\right)^{2}}}{\sqrt{\frac{1}{n^{2}-1} \sum_{i=1}^{n} \sum_{j=1}^{n}\left(l_{i j}-\frac{1}{n^{2}} \sum_{i=1}^{n} \sum_{j=1}^{n} l_{i j}\right)^{2}}} \quad(\mathrm{j}=1, \ldots ., \mathrm{n})
\end{aligned}
$$

When $V_{i, j}>1$ it implies sectoral variance is above average relative to other sectors of the economy and therefore receives (supplies) goods and services from (to) only a few sectors in the economy.

\subsubsection{Hypothetical Extraction}

Finally, the hypothetical extraction method (HEM) can be used to estimate the value a sector has within the economy by its contribution to overall economic output. This method was originally developed by Strassert (1968) and empirically implemented by Schultz and Schumacher (1976), Schultz 1977). The normalized backward and forward linkage was then proposed by Temurshoev and Oosterhaven (2014) and overcame several of the previous limitations with the original HEM. The objective of the HEM is

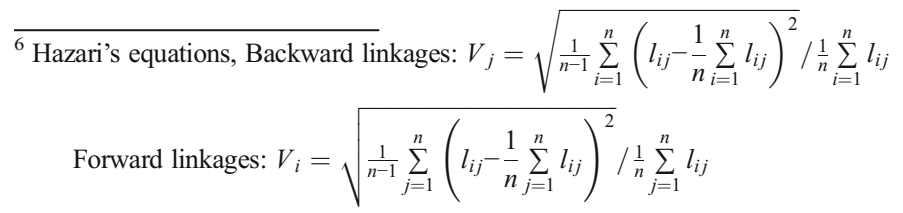


to quantify how total output of an economy changes if that sector were eliminated from the economy. This is achieved by removing the $i$-th row and $j$-th column of the input matrix A, and then using the basic Leontief equation (Eq. 1.15) to compute the reduced outputs in the hypothetical case. ${ }^{7}$ In the real economy, should an entire sector be removed without external substitution, total output including all income and jobs must also go to zero. Removing a sector is therefore treated as 'hypothetical' and used to ascertain the underlying importance of a sector within the economy. Fundamentally, the purpose of this measure is to analytically and empirically compare the outcome of different key sectors on the economy using a dimensionless normalized hypothetical extraction linkage per unit of input or output (Oosterhaven and Stelder 2002). In Eq. (1.16), the terms $\mathbf{x}_{\mathrm{L}}^{-i}$ and $\mathbf{x}_{\mathrm{G}}^{-i}$ represent the total hypothetical output of the economy using the Leontief and Ghosh approaches respectively (the final demand and value added vectors also exclude The $i$-th component shown by $\mathbf{f}^{-i}$ and $\mathbf{v}^{-i}$ where the minus sign shows that the $\mathrm{i}$-th sector has been removed from the equation)

$$
\mathbf{x}_{L}^{-i}=\left(\mathbf{I}-\mathbf{A}^{-i}\right)^{-1} \mathrm{f}^{-i} \text { and } \quad \mathbf{x}_{G}^{-i}=\mathbf{v}^{-i}\left(\mathbf{I}-\mathbf{B}^{-i}\right)^{-1}
$$

According to Oosterhaven an industry's backward and forward normalized linkage due to its complete extraction can be calculated from its backward impact, $\left(\mathbf{i}^{\prime} \mathbf{x}-\mathbf{i}^{\prime} \mathbf{x}_{L}^{-i}\right)$ / $\mathbf{x}_{i}$, or its total forward impact, $\left(\mathbf{x}^{\prime} \mathbf{i}-\left(\mathbf{x}_{G}^{-i}\right)^{\prime} \mathbf{i}\right) / \mathbf{x}_{i}$, divided by its own total output. The difference between total outputs of the economy before and after the extraction is called the 'total linkage' and measures the gross contribution of Sector $i$ to the economy.

$$
G_{i}=\mathbf{i}^{\prime} \mathbf{x}-\mathbf{i}^{\prime} \mathbf{x}_{l}^{-i}
$$

If this was done for every sector in the economy and these totals were added together, the total gross contribution from each sector would be greater than the total output of the entire economy, representing double counting in the round by round economic contributions. To this end, a net hypothetical extraction indicator is proposed to estimate the financial contributions made by infrastructure. First, gross total contribution is calculated for each infrastructure sector that includes the direct and indirect effects of infrastructure $i$ on the whole economy (Eq. 1.18). The corollary of the $i$-th sector's gross contribution to the economy, is the contribution of all remaining sectors to the $i$-th sector (Eq. 1.18).

$$
\mathbf{N}_{i}=\mathbf{i}^{\prime} \mathbf{x}-\mathbf{i}^{\prime} \mathbf{x}_{L}^{-i}-\mathbf{i}^{\prime} \mathbf{x}_{L}^{(i)}
$$

The term $\mathbf{i}^{\prime} \mathbf{x}_{L}^{(i)}$ represents the total output of the economy if every sector in the economy were set to zero except the $i$-th sector. Thus $\mathbf{x}_{L}^{(i)}=\left(\mathbf{I}-\mathbf{A}^{(i)}\right)^{-1} \mathbf{f}^{(i)}$, where $\mathbf{A}^{(i)}$ is a matrix of zeros except the row and column of the $i$-th sector and similarly $\mathbf{f}^{(i)}$ is a vector of zeros except the $i$-th sector.

\subsubsection{Income Multipliers}

Income multipliers for each of the nine infrastructure sectors are also considered. The structural macroeconomic effects of employment are known to vary by economic sector. Income multipliers measure the change in income through compensation to employees through the economy as a result of changes to final demand. Direct income multipliers

\footnotetext{
${ }^{7}$ An efficient method for estimating HEM was developed by Temurshoev (2010).
} 
(labour-input coefficients) measure the direct contribution to employees in sector $j$ due to a unit change in final demand in sector $i$. Direct impacts are thus the first round of impacts that occur on an industry to satisfy an increase in final demand from that industry.

$$
c_{j}=\frac{Y_{j}}{X_{j}}
$$

From Eq. $1.19 c_{j}$, represents the direct income generated for each unit of output from sector $j$; $Y_{j}$ represents the compensation to employees in sector $j$ and $X_{j}$ represents total output from sector $j$. The term $c_{j}$ therefore represents a measure of the direct compensation to employees due to an increase in demand from sector $j$. Indirect impacts or 'simple multipliers' are the additional economy wide impacts that must also increase to meet an increase in final demand. Type I income multipliers consider both direct and indirect flows within the economy relative to the employee compensation from the $j$-th sector. When estimating Type I multipliers it is therefore necessary to invoke the Leontief inverse to calculate the additional requirements in production required from the rest of the economy to meet a unit increase in output from sector $i$. The so-called Type 1 net income multipliers are given by Eqs. 1.20 and 1.21, where the latter is normalized with respect to income.

$$
\begin{gathered}
m(h)_{j}^{I}=\sum_{i=1}^{n} c_{j} l_{i j} f_{c, i} \\
\overline{m(h)_{j}^{I}}=\frac{\sum_{i=1}^{n} c_{j} l_{i j} f_{c, i}}{c_{j}} .
\end{gathered}
$$

The term $m(h)_{j}^{\mathrm{I}}$ from Eq. 1.20 gives the standard net income multiplier for each sector of the economy. The term $c_{j}$ represents a row vector of direct income requirements (labour-input coefficients), $L_{i j}$ is the Leontief inverse and $f_{c, i}$ is a column vector of exogenous final demand coefficients (i. e $f_{j} / x_{j}$ ). The term $\overline{m(h)}{ }_{j}$ represents the normalized version of the Type 1 net income multiplier and represents the increase in absolute income from $c_{j}$ required to match an increase in final demand. Equation 1.21 is therefore a relative or normalized measure and depends on the existing employee compensation for each sector.

Type II multipliers are estimated similarly to Type I income multipliers but first the model needs to endogenise the influence of household spending and income within the economy. This is achieved by endogenising compensation to employees (income) as a row vector and household final demand as column vector within the direct requirements matrix. Each row element, $i$ is then divided by total Output $X_{i}$ giving, $\mathbf{A}^{*}$ the new expanded technical coefficient matrix. The Leontief inverse is then estimated in the normal fashion using $\mathbf{L}^{*}=\left(\mathbf{I}-\mathbf{A}^{*}\right)$ where the elements of $\mathbf{L}^{*}$ thus include the direct, indirect and induced effects of employment income. Type II net income multipliers are then derived from the newly estimated $\mathbf{L}^{*}$ matrix from Eq. 1.22 and for the net normalized variant the multipliers are estimated using Eq. 1.23.

$$
m(h)_{j}^{I I}=\sum_{i=1}^{n} c_{j} l_{j j}^{*} f_{c} .
$$




$$
\overline{m(h)_{j}^{I I}}=\frac{\sum_{i=1}^{n} c_{j} l_{j j}^{*}}{c_{j}} .
$$

Endogenising income is done to capture Keynesian based induced income effects where additional compensation to employees will lead to further expenditure on goods and services in the economy having the effect of increasing demand even further than just considering indirect effects alone. Endogenising the effects of employment is therefore accomplished by augmenting the technical coefficient matrix with the household sector (employee compensation and the household portion of final demand). This opens up the possibility for exaggerating the effects of increased income on economic output. This is because increases to income lead to increased spending which results in increased output which leads to further increases to income and so on. As some income is invariably saved rather than spent this exaggerates the multiplier effects of income.

The interpretation of the total income multiplier is that it measures the increase in direct, indirect and induced income required to meet a unit increase in new demand from sector $j$ output. Similarly, normalized income multipliers estimate the expansion of incomes relative to existing incomes, and for Type II multipliers these also include the induced effects of increased household spending as a consequence of increased income. Thus, the induced Type II multiplier effect described by Eq. 1.22 estimates the additional induced compensation to employees due to an increased final demand. ${ }^{8}$ The normalized Type II income multiplier places this estimate relative to existing employee compensation. A sector with low initial employee compensation may expand quickly when indirect and induced effects are considered, giving a large normalized multiplier; however, the total value of expansion in income may still be low when compared against other sectors in the economy in absolute terms. ${ }^{9}$

In order to get a true picture for the effect of income effects from different infrastructure sectors it is necessary to employ a variation of the hypothetical extraction method. Similar to the hypothetical extraction method already employed we define a complete technical coefficient matrix $\mathbf{A}$ and a second technical coefficient matrix $\mathbf{A}_{\mathrm{j}}^{*}$ obtained by replacing the row and column of the corresponding sector $j$ with zeros. Then by defining a vector of direct employment coefficients $\lambda$ and a corresponding vector where the employment coefficients for sector $j$ have been extracted and replaced with zeros, $\lambda_{j}^{*}$, it is possible to estimate the total employment linkages of sector $j$ with the rest of the economy. This is given by Eq. (1.24).

$$
T E L_{j}=\lambda^{\prime}(\mathbf{I}-\mathbf{A})^{-1} \mathbf{i}-\lambda_{j}^{*}\left(\mathbf{I}-\mathbf{A}_{j}^{*}\right)^{-1} \mathrm{i}
$$

In Eq. (1.24) $\mathrm{i}$ is a summation vector and $\mathbf{I}$ is the identity matrix. $T E L_{j}$ is therefore interpreted as the total employment linkages of sector $j$. In other words $T E L_{j}$ summarizes the impact on employment income directly for sector $j$ but also indirectly from other sectors in the economy which are also affected (Meller and Marfán 1981). After estimating $T E L_{j}$ for each sector of the economy it is then possible to estimate the

\footnotetext{
${ }^{8}$ Endogenising household income requires that changes to final demand only occur due to shifts in components other than household income such that $\mathbf{x}=\mathbf{L f}$ becomes $\mathbf{x}=\mathbf{L} * \mathbf{f} *$ once incomes have been endogenised.

${ }^{9}$ A large normalised multiplier does not necessary mean a large absolute increase in income.
} 
percentage by which income generated in the economy would reduce if sector $j$ were hypothetically extracted from the economy.

$$
\% L a b_{j}=\frac{T E L_{j}}{T E L} \times 100
$$

\section{Data}

Data used in this analysis are from the 2005 UK Input-output Analytical Tables (IOATs) and are the most recent tables produced by the Office for National Statistics available online (ONS 2011). The tables are consistent with the 2009 editions of the United Kingdom National Accounts: The Blue Book (ONS 2009a) and the United Kingdom Balance of Payments: The pink book (ONS 2009b). The Supply and Use Tables (SUTs) are used to calculate the IOATs and provide a picture of the flows of products and services in the economy for a single year. They show the composition of uses and resources across institutional sectors and the inter-dependence of industries in order to reconcile production, income and expenditure approaches to the measurement of GDP. The presentation of the SUTs and IOATs are based on the European System of Accounts which itself is based on the United Nations System of National Accounts.

The 2005 IOATs are derived using 108 sector input-output groups (IOGs) consistent with the UK's Standard Industrial Classification 2003 (SIC (03)) for industries and Eurostat's Classification for Products by Activity (CPA (02)) for products. Including components of non-market output produced by general government and non-profit institutions serving households (NPISHs) the 108 sector IOGs are expanded to 123 sectors.

Using Input-output aggregation methods the 123 sectors represented within the input-output tables were reduced to 38 sectors to assist with interpretation, reporting and comparison. Aggregation of input-output matrices clearly leads to a loss of information and may change the conclusions that can be taken from the analysis depending on how the matrices have been aggregated (Weber 2009). A list of these 38 sectors can be viewed in Appendix A and are based on the NACE 1.1 section classifications. During the aggregation procedure each infrastructure sector was retained making it possible to compare each infrastructure sector against each of the other sectors within the UK economy. With the exception of land transport each infrastructure sector was identified uniquely in the 2005 UK input-output tables. For the case of land transport, economic activity was split across two sectors within the input-output tables and so 'other land transport' and motor vehicle distribution \& repair, fuel' were added together for the purposes of this analysis. ${ }^{10}$

\footnotetext{
10 'Other Land Transport' includes all land transport used for commercial purposes including activities providing urban or suburban transport of passengers on scheduled routes following a normally fixed time schedule. Transport services may be carried out with motorbus, tramway, streetcar, trolleybus, underground and elevated urban railways, etc. It also includes transport by taxis, operation of school buses and coaches and freight transport by road. This sector excludes auxiliary transport services such as cargo handling, warehousing, repair and maintenance of transport facilities such as railway terminals and infrastructure and the operation of airport terminals. It also excludes transport via pipelines. This sector excludes the sale of fuel. The sector 'motor vehicle distribution \& repair, fuel' includes the retail sale of fuel and the maintenance and repair of motorcycles and motor vehicles but excludes vehicle manufacture and rent.
} 


\section{Results}

\subsection{Backward and Forward Linkages}

Sector 'keyness' is a relative concept and dependent on other sectors in the economy. Therefore, normalizing each sector's 'keyness' allows the relative linkage effect of each sector to be determined. The analysis refers to each of the 38 economic sectors defined in Annex (1). Equations 1.9-1.12 were used to create the bar graph in Fig. 5 and shows the normalized direct backward linkages. It is clear that (18) Electricity production and distribution, (19) Gas distribution and (22) Land transport have above average direct backward linkage dependence with other sectors in the economy (i.e., they are directly highly reliant on other sectors of the economy for the provision of goods and services).

All remaining infrastructure sectors have below average backward dependence while (29) Telecommunications and (20) Water supply have the lowest overall direct backward dependence on other sectors for the supply of goods and services. The top five most important sectors are ranked for each infrastructure sector and represented by different colours on the stacked bar chart; white indicates the combined importance of the remaining 33 sectors with lowest linkage measures. As shown in Fig. 5, the top five most important sectors for backward dependence in each infrastructure sector are able to explain over two-thirds of each infrastructure's relative direct backward linkage dependence across all infrastructure sectors. Both (19) Gas distribution and (18) Electricity production and distribution depend heavily on (3) Coal, gas mining and extraction and (18) Electricity production and distribution. ${ }^{11}$ For the other infrastructure sectors there are several sectors that stand out as important: (31) Business services and real estate is an important sector across all infrastructure sectors; (4) Postal and courier services is an important sector for all transport sectors and (18) Electricity production and distribution is important for (20) Water supply and (22) Land transport.

Five infrastructure sectors have above average direct forward linkage effects when compared with the rest of the economy. These are (35) Sewerage and sanitary services; (29) Telecommunications; (25) Railway transport; (19) Gas distribution and (18) Electricity production and distribution. The first five most important sectors are generally not as important for direct forward linkages as direct backward linkages, but still explain a large proportion of the normalized forward linkage effect. Important economic sectors that rely on infrastructure services include (31) Business services and real estate; (23) Wholesale and retail distribution; and (38) Non Profit Institutions Serving Households (NPISH's).

Sectors with linkage effects greater than 1.0 indicate above average contribution, while sectors with linkage effects less than 1.0 represent below average contribution. The bar titled 'Average effects' has been included for comparison, and is a hypothetical example for what the average sector would look like. The average sector therefore has a backward and forward linkage effect of 1.0 and each sector linked to the average sector contributes equally (i.e., 1/38 of that sectors linkage dependence). For the remaining nine infrastructure sectors the five most important economic sectors have been ranked and given a colour based on that rank. Therefore, each infrastructure sector's total input dependence (backward linkage) and total output dependence (forward linkage) are provided. The white

${ }^{11}$ Electricity production and distribution relies heavily on itself in the production of electricity. 

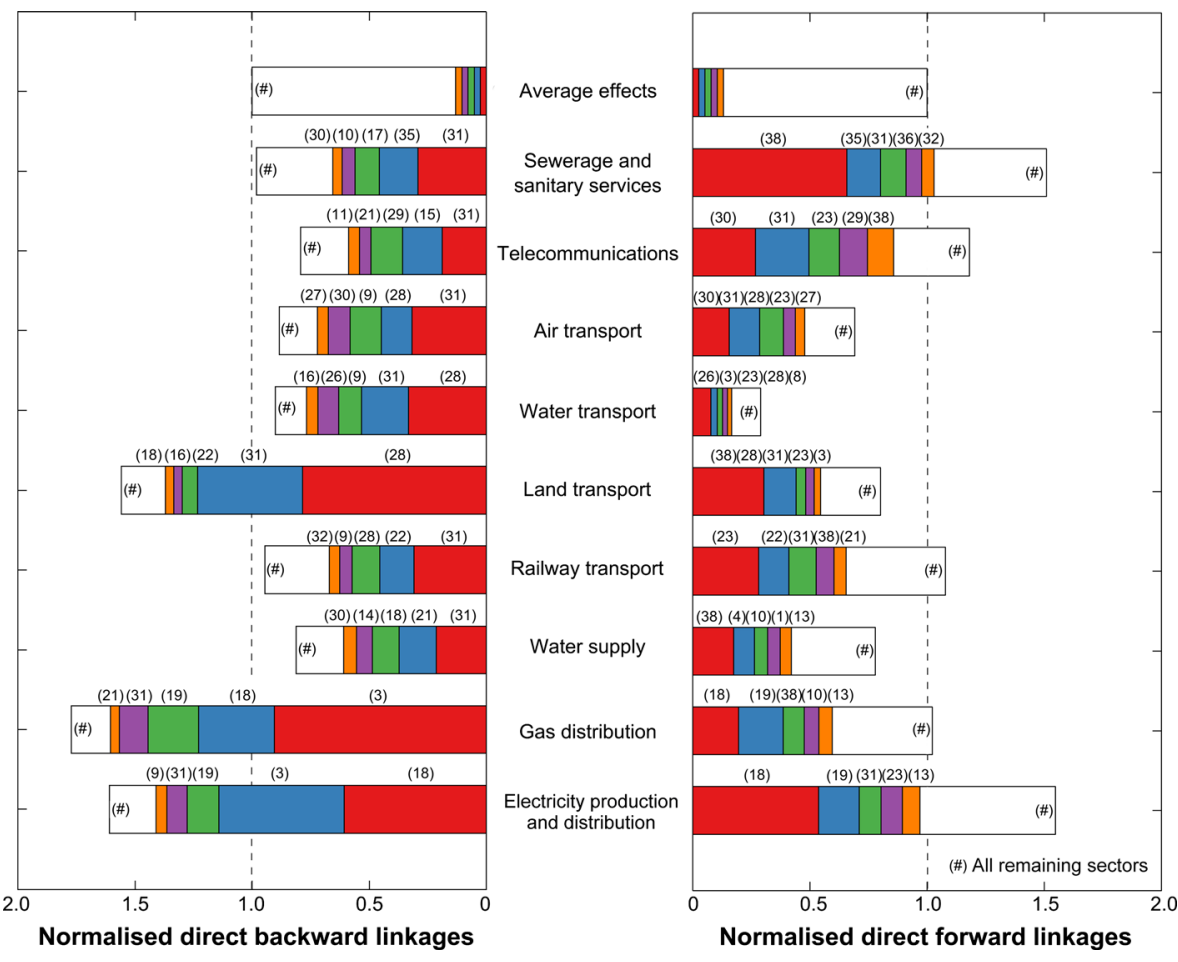

Fig. 5 Normalised direct backward and forward linkage effects of infrastructure 'keyness'

portion on each bar labeled with a hash tag represents the sum of all remaining sectors of the economy either supplying or selling to each infrastructure sector.

Total effects on the other hand consider the round-by-round transactions that occur within an economy. Unlike direct effects, total effects consider disruptions through the entire supply chain and therefore give a better indication for how the economy is affected overall. As shown in Fig. 6 the total backward linkage effect is above average for (18) Electricity production and distribution; (19) Gas distribution and (22) Land transport. Total backward linkages are below average for every other infrastructure sector. When compared to direct effects the top five ranked sectors for total backward linkages explain a larger proportion of the linkage effect suggesting a few sectors have significant influence over infrastructure. When looking across all infrastructure sectors for total backward linkages, the most important sectors for infrastructure are (31) Business services and real estate, (30) Banking finance and insurance and (9) Coke ovens, refined petroleum and nuclear fuel. Once more, (28) Postal and courier services has significant backward linkage effects across all transport sectors suggesting purchases a large share of transport services. For forward total linkages five infrastructure sectors have higher than average linkage effects. These are: (35) Sewerage and sanitary services, (29) Telecommunications; (25) Railway transport; (18) Gas distribution; and, (19) Electricity production and distribution. The most important forward linkage sectors with infrastructure are (31) Business services and real estate; (23) Wholesale and retail distribution; and, (38) Non Profit Institutions Serving Households (NPISH's). Sectors that have high forward dependence are sectors that rely on the services provided by infrastructure. 

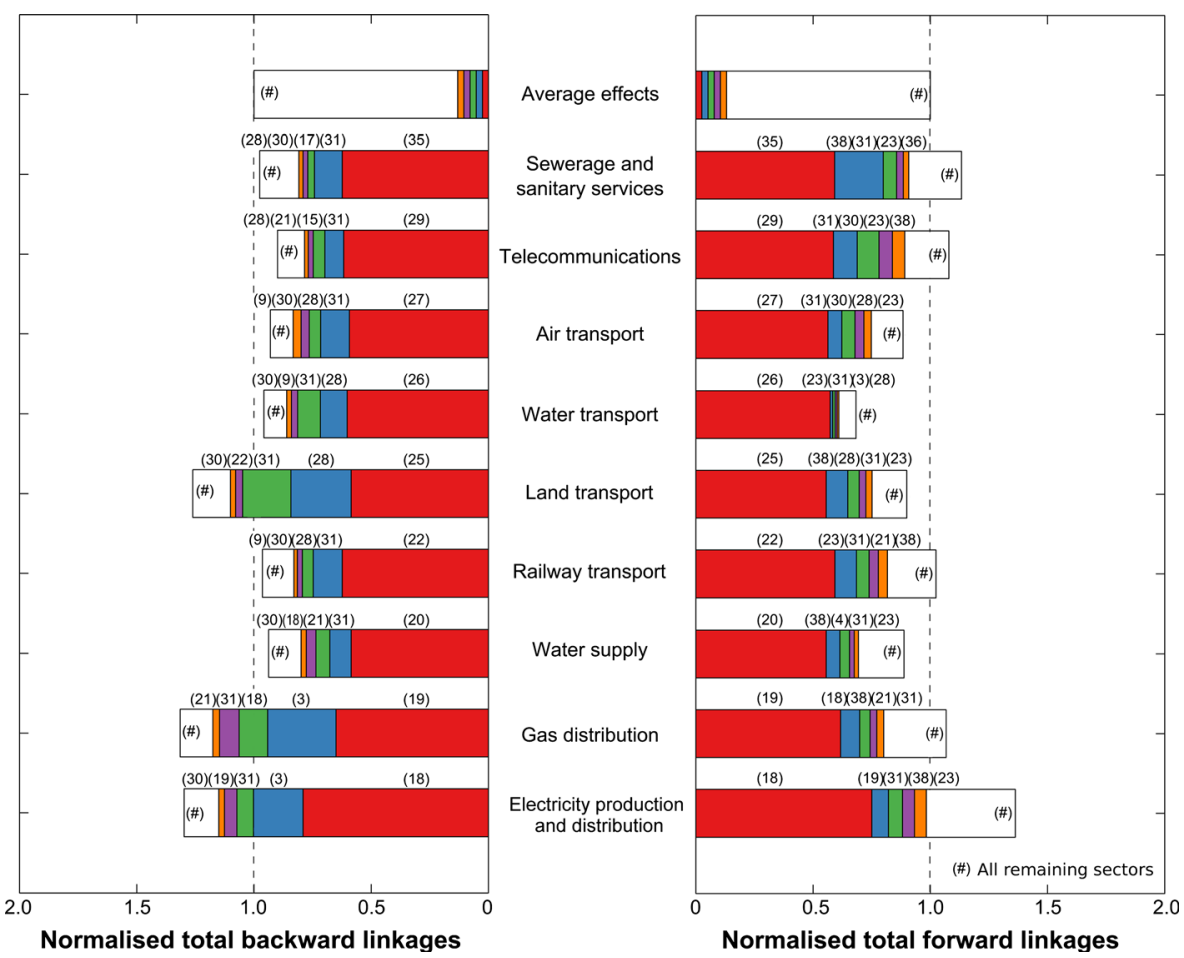

Fig. 6 Normalised total backward and forward linkage effects of infrastructure 'keyness'

\subsection{Coefficient of Variation}

The variance or spread of the number of sectors purchasing or selling goods and services is an important indicator of vulnerability. If a sector sells its goods and services to a relatively small number of sectors or if infrastructure relies on goods and services from a small number of sectors then it may be vulnerable to disruptions occurring within its supply chain. In Fig. 7 the backward and forward variance for each sector of the economy is shown and calculated using Eqs. 1.13 and 1.14. It is immediately obvious that far more sectors of the economy have higher forward variance than backward variance. This suggests that most sectors receive their goods and services relatively evenly from a large number of sectors in the economy (backward variance) but when it comes to the supply of goods and services, most sectors supply to a relatively small number of other sectors. Infrastructure appears to stand out as an exception to this general rule. For example (19) Gas distribution, (25) Railway transport and (26) Water transport appear to have higher backward variance when compared to forward variance. This suggests that infrastructure sectors rely on relatively few sectors of the economy to produce goods and services but then sell their goods and services to a relatively large number of other sectors of the economy.

Relative variance is an indicator of diversity for both the demand (backward linkage) and supply (forward linkage) of goods and services in the economy. Values greater than 1.0 indicate above average variance relative the variance across the whole economy. Intra-sectoral demand and supply (that is the provision and supply of goods and 

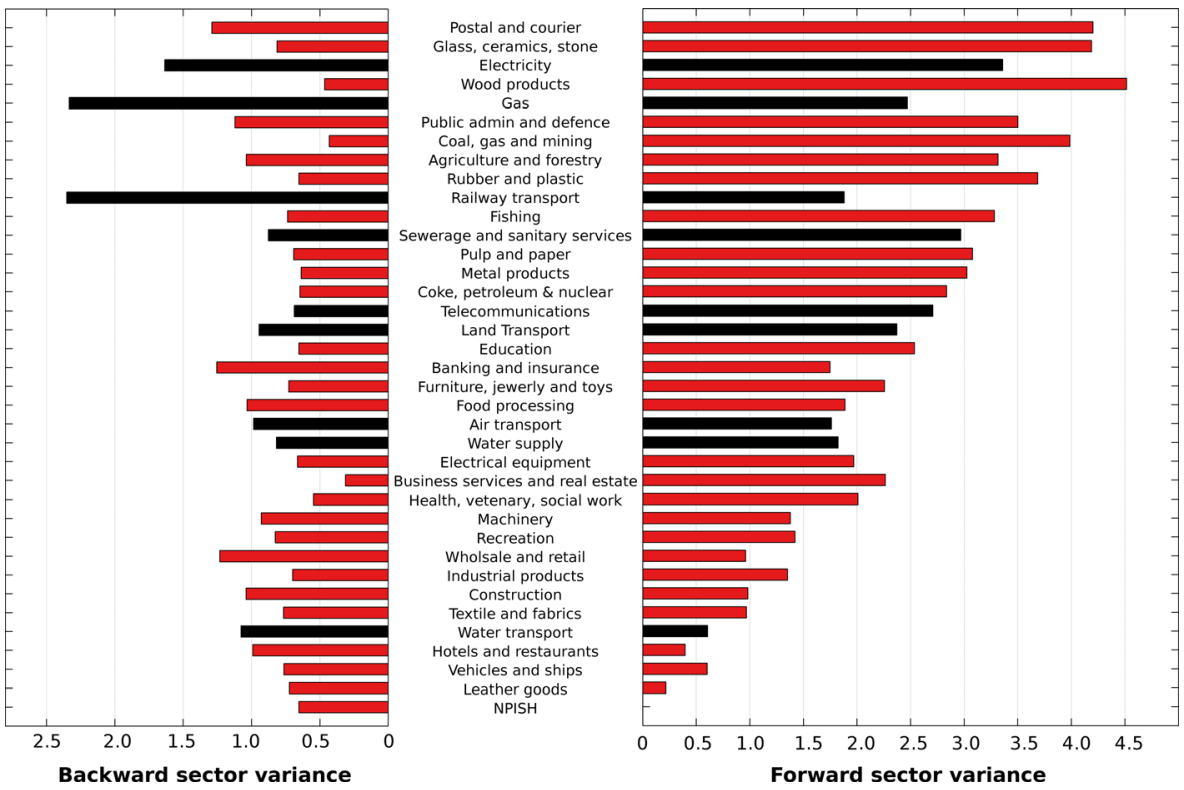

Fig. 7 Backward and forward linkage variance for multiple sectors

services within a single sector) have been netted out. This is because we are interested in understanding the diversity of trade external to each sector. A sector with high variance indicates significant trade across only a few sectors while low variance indicates trade that is spread relatively evenly across different sectors. The sum of backward variance and forward variance has been ranked from highest to lowest.

\subsection{Hypothetical Extraction}

The net economic contribution from each infrastructure sector is calculated using the hypothetical extraction method as outlined in Section 2.2.4. This process involves hypothetically removing a specific sector from the UK economy and then reestimating total output. The subsequent decrease in total output can then be attributed as the hypothetical value that sector provides to the economy overall. Estimating the relative value of final demand and intermediate demand is achieved by also hypothetically removing final demand for the sector being analyzed and comparing this with the overall decrease in output. As shown in Table 2 the value that each infrastructure sector provides to the economy varies significantly. (22) Land transport provides the largest economic value to the economy followed by (35) Telecommunications and (18) Electricity production and distribution. The gross economic contribution using hypothetical extraction estimates the round by round effects of the contribution from the $i$-th sector on the economy. Thus, the total decrease in economic output from this sector will lead to a much greater decrease in economic output when compared to the contribution made by this sector on its own. Thus a net economic contribution is provided using Eq. 1.18. Table 2 shows that (22) Land Transport; (18) Electricity Production and Distribution and (29) Telecommunications are the most important infrastructure sectors in terms of contribution to the overall economy. 
Table 2 Estimated economic value of infrastructure systems as function of total output

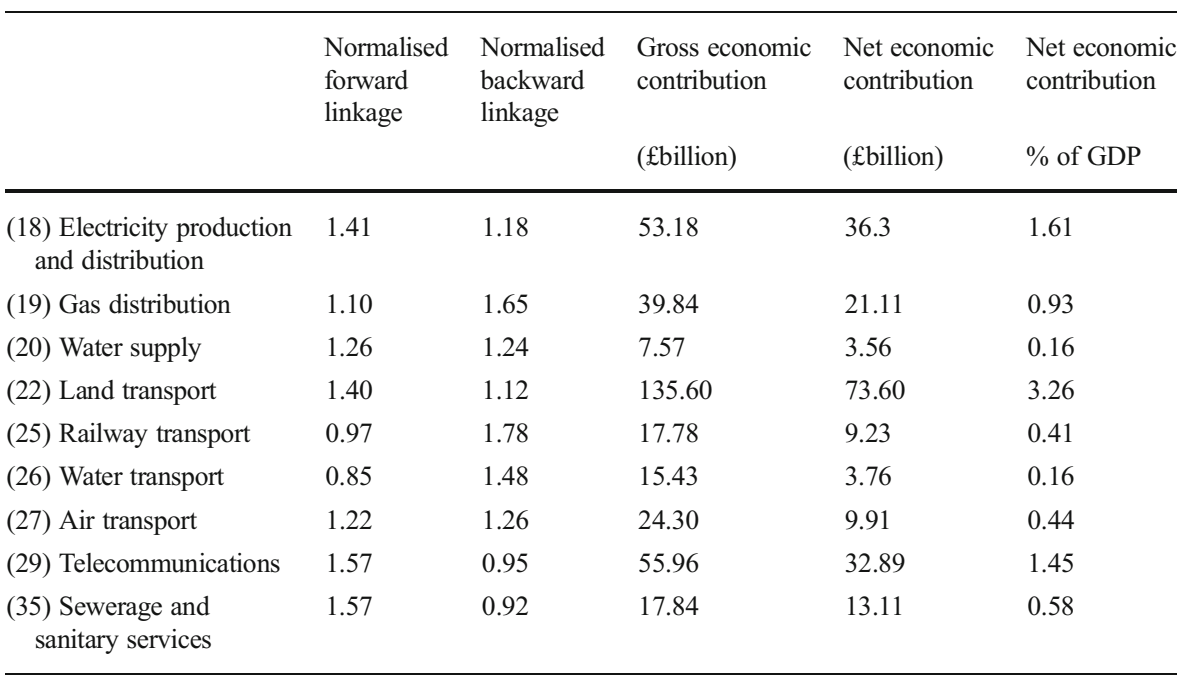

\subsection{Income Multipliers}

Direct, indirect and induced income multipliers are shown in Fig. 7. Direct income multipliers represent the direct increase in compensation to employees if final demand in that sector increased by one unit. For example, (35) Sewerage and sanitary services has a direct income multiplier of 0.36. If final demand for Sewerage and Sanitary Services were to increase by $£ 100$ then $£ 36$ of that $£ 100$ increase would go towards compensating employees in the Sewerage and Sanitary Services sector. Indirect income multipliers consider how other sectors of the economy must increase production to meet additional final demand in the Sewerage and Sanitary Services sector. The indirect income multiplier for Sewerage and Sanitary Services is 0.19 therefore $£ 19$ will be generated in the economy and spent on additional compensation for employees elsewhere in the economy. If induced effects are also taken into account (additional expenditure on goods and services due to increased incomes going to employees) then output in the economy would increase, and an additional 0.31 or $£ 31$ will be spent on compensation to employees within the economy. Thus the total compensation to employees including all effects is the amount of increase estimated by the closed input output model. For Sewerage and Sanitary Services this will be 0.86 or $£ 86$.

The closed model represents induced effects and over-estimates the income multiplier effect as not all additional income earned is spent in the economy. On the other hand, a model that only represents indirect effects probably underestimates the benefits to the economy, as higher incomes will lead to additional expenditure. Oosterhaven et al. (1986) recommend using indirect and induced multipliers as the upper and lower bounds of the true indirect effect on the economy. Figure 8 shows the direct, indirect and induced increase in incomes for a unitary increase in final demand from each sector of the economy. 


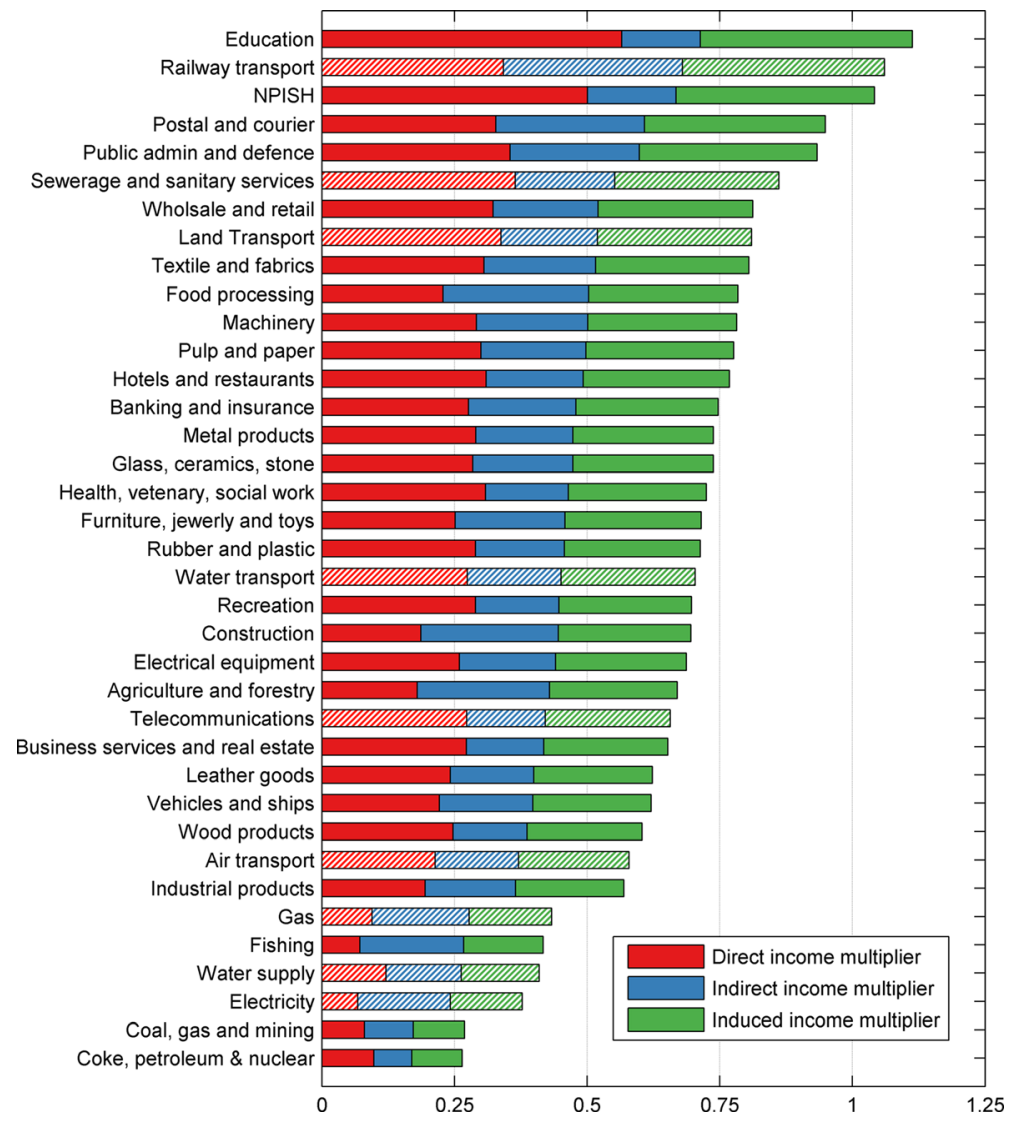

Fig. 8 Direct, indirect and induced income multipliers for 38 economic sectors in the UK

In contrast to the simple multipliers shown in Fig. 8, normalized multipliers are used to show how much incomes expand relative to the existing level of income. Normalized Type I and Type II multipliers are therefore relative to the direct income multiplier and do not provide an account of the absolute quantity that incomes will expand in the economy but instead how much incomes will expand relative to that sectors existing income. For example, a sector with a small absolute income might have a small simple multiplier representing a small absolute increase in income, but the same sector may have a large normalized multiplier suggesting the relative expansion of incomes in that sector may expand by a large margin. It is therefore important to distinguish between these two types of multiplier effects. Type I and Type II multiplier effects are shown in Table 3 for each infrastructure sector.

It is notable that (18) Electricity Production and Distribution and (19) Gas Distribution have some of the lowest simple multiplier effects suggesting a smaller share of increases to final demand goes on compensation to employees in absolute terms, but these two sectors also have some of the largest Type I and Type II multipliers when compared with other sectors in the economy, suggesting a large increase in relative terms. This implies that increases occurring to final demand in (18) Electricity Production and (19) Gas Distribution expand incomes 
Table 3 Income multiplier effects from infrastructure

\begin{tabular}{llll}
\hline & $\begin{array}{l}\text { Type I Income } \\
\text { multiplier }\end{array}$ & $\begin{array}{l}\text { Type II income } \\
\text { multiplier }\end{array}$ & $\begin{array}{l}\text { Hypothetical contribution to } \\
\text { employment income }(\%)\end{array}$ \\
\hline (18) Electricity production and distribution & 3.56 & 5.56 & 2.39 \\
(19) Gas distribution & 2.93 & 4.57 & 2.19 \\
(20) Water supply & 2.17 & 3.38 & 1.61 \\
(22) Land transport & 1.54 & 2.40 & 6.35 \\
(25) Railway transport & 2.00 & 3.10 & 4.26 \\
(26) Water transport & 1.65 & 2.57 & 2.71 \\
(27) Air transport & 1.74 & 2.71 & 2.40 \\
(29) Telecommunications & 1.54 & 2.41 & 3.46 \\
(35) Sewerage and sanitary services & 1.52 & 2.36 & 3.69 \\
Average for infrastructure & 2.07 & 3.22 & 3.23 \\
Average for all sectors & 1.84 & 2.88 & 3.98 \\
\hline
\end{tabular}

disproportionately in the rest of economy (indirect and induced effects) than increases in income occurring directly in these sectors alone. The average income multiplier across all infrastructure sectors is higher than the average income multiplier across all sectors in the economy. This suggests that infrastructure has larger indirect and induced effects on income than the average induced and indirect effects for the average sector. Infrastructure sectors are therefore important employers in the national economy.

Using the hypothetical extraction method, it is possible to determine how much employment income in the whole economy would decrease if sector $j$ were removed from the economy. This is therefore a measure of how important a particular sector is at generating employment income in the economy. This analysis is completed for each infrastructure sector of the economy. Table 3 gives the Type I income multipliers, Type II income multipliers and the hypothetical contribution to employment income for each infrastructure sector. The last column in Table 3, (22) Land Transport has the most significant effect on employment income followed by (25) Railway Transport (35) Sewerage and Sanitary services and (29) Telecommunications. The highest value sectors across the whole economy in generating employment income are (31) Business Services Real Estate sector responsible for $13.68 \%$ of income, followed by (28) Postal and Courier Services with $8.03 \%$ and (23) Wholesale and Retail with $7.44 \%$.

\section{Conclusion}

In this article an in-depth analysis of the inter-linkages and economic contributions from infrastructure within the UK economy has been explored. Over the last 23 years there has been a decline in the relative economic contribution from infrastructure to UK GVA. The only infrastructure sectors to increase their relative contribution to GVA since 1992 were (26) Water and (35) Sewerage and Sanitary services. On the 
other hand, (25) Railway transport and (19) Gas Distribution have had the largest relative decline in contribution towards UK GVA with relative contributions decreasing by over $50 \%$ since 1992 .

This relative decline may be because the UK economy has evolved in such a way that it depends less on infrastructure systems for providing economic output. Alternatively, it could simply reflect there has been a serious under investment in critical infrastructure over the last two decades. This in turn has resulted in deteriorating infrastructure that is less capable of keeping pace with economic output. In order to understand the function of infrastructure within an economy, it is necessary to explore its economic linkages and that has been the objective of this article.

Miller and Temurshoev (2013) show that the relative position of sectors and countries within a production chain can be represented by the industries 'output upstreamness' and 'input downstreamness' which is shown to be equivalent to a sectors TBL and TFL respectively. By definition, infrastructure sectors are located more upstream along the production chain relative to other industries. This observation is consistent with the results presented in this analysis. Infrastructure sectors are found to have high TFL and therefore dependent on inter-industry demand, placing them further upstream in the supply chain.

For direct backward linkages (19) Gas Distribution, (18) Electricity Production and (22) Land Transport are ranked as the three highest sectors for backward dependence in the entire economy. For forward direct linkages (18) Electricity Production is ranked $5^{\text {th }}$ most important in the economy and (35) Sewerage and Sanitary Services is ranked $6^{\text {th }}$. The top five most important economic sectors contribute more than two-thirds of total output from each infrastructure sector. Five infrastructure sectors have higher than average direct forward linkages. These are in order of size: (35) Sewerage and Sanitary Services, (18) Electricity Production, (29) Telecommunications, (25) Railway Transport and (19) Gas Distribution.

When analyzing total linkages, (18) Electricity Production, (19) Gas Distribution and (22) Land Transport once again have higher than average backward linkages. Similarly, for total forward linkages the same five infrastructure sectors have higher than average forward linkage effects but their order has changed to the following: (18) Electricity Production, (35) Sewerage and Sanitary Services, (29) Telecommunications, (19) Gas Distribution and (25) Railway Transport. Once again, there are just five non-infrastructure sectors trading with each infrastructure sector that are able to explain the majority of economic activity. Across all sectors, intra-sectoral demand accounts for the highest proportion of economic activity when total linkages are considered.

When considering linkage variance, an interesting pattern starts to emerge. Unlike other sectors of the economy, infrastructure appears to have higher backward sector variance than forward sector variance implying that infrastructure relies heavily on only a few sectors for the provision of goods and services and sells goods and services across a larger number of other sectors within the economy. This is in contrast to the majority of other economic sectors where the reverse is true and suggests that infrastructure sectors are highly dependent on the provision of goods and services from a few sectors but have demand for their goods and services spread relatively evenly across all other sectors of the economy. 
Using the hypothetical extraction method it is possible to estimate the economic value that different UK infrastructure sectors may contribute to the UK economy taking into consideration both direct and indirect effects. The net hypothetical contribution made by each of the top four infrastructure sectors from highest to lowest were: (22) Land Transport (£73.6b), (18) Electricity Production (£36.3b), (29) Telecommunications (£32.89b), and (19) Gas Distribution (£21.11b).

Using Type I income multipliers, it is possible to determine which sectors contribute the most to income. These are in order of importance, (25) Railway Transport, (35) Sewerage and Sanitary Services and (22) Land Transport. Closing the model with respect to households and including induced effects means that for every $£ 1$ increase in final demand in any one of these sectors will lead to an increase of more than $£ 0.75$ in additional employment income in the economy. Estimating Type I and Type II multiplier effects for each infrastructure sector provides an estimate for how incomes will expand (multiply) by an increase to final demand. Using this estimate (18) Electricity Production and (19) Gas Distribution have the highest Type I and Type II multiplier effects when compared against other infrastructure sectors. When compared against other sectors of the economy, infrastructure has above average indirect income effects across the economy. Using the hypothetical extraction method to study the effects of income on infrastructure, we show that (22) Land transport and (25) Railway Transport contribute the largest share of employment income across the infrastructure sectors and above average employment income to the economy as a whole.

This study explored the economic relationships between nine infrastructure sectors with the rest of the UK economy. Using key-linkages analysis it has been possible to show what sectors depend on infrastructure and how infrastructure depends on other sectors. Each infrastructure sector is shown to be unique in the way it interacts with other economic sectors and in the form of contribution it makes to the economy overall. Infrastructure is therefore a necessary and important part of economic development. Although it is difficult to quantify the true value that infrastructure provides within an economy this paper provides a good first attempt at quantifying the structure of the relationships between different infrastructure sectors and their overall contribution to output. In conclusion, infrastructure remains an integral component of the UK economy. Further research is required to understand how infrastructure may co-evolve with the economy in the near and distant future and what this might mean for economic development.

Acknowledgments Funding for this research was provided by the Engineering and Physical Sciences Research Council (EPSRC) grant number EP/101344X/1 through the Infrastructure Transitions Research Consortium (ITRC). The authors would like to acknowledge the host institution, the University of Cambridge. Special acknowledgement is also given to the reviewers who have provided thoughtful and provocative suggestions throughout the review process and whose comments were invaluable, adding insight and refining the methods that were used in this paper. The views expressed in this paper are those of the authors' alone.

Open Access This article is distributed under the terms of the Creative Commons Attribution 4.0 International License (http://creativecommons.org/licenses/by/4.0/), which permits unrestricted use, distribution, and reproduction in any medium, provided you give appropriate credit to the original author(s) and the source, provide a link to the Creative Commons license, and indicate if changes were made. 


\section{Appendix 1}

Table 4 Infrastructure categories

\begin{tabular}{|c|c|c|c|c|c|}
\hline 1 & Agriculture and forestry & 14 & Machinery & 27 & Air transport \\
\hline 2 & Fishing & 15 & Electrical equipment & 28 & Postal and courier services \\
\hline 3 & Coal, gas mining extraction & 16 & $\begin{array}{l}\text { Motor vehicles, ship } \\
\text { building and repair }\end{array}$ & 29 & Telecommunications \\
\hline 4 & Food processing & 17 & $\begin{array}{l}\text { Furniture, jewellery, } \\
\text { sports equipment, toys }\end{array}$ & 30 & Banking finance, insurance \\
\hline 5 & Textile and fabrics & 18 & $\begin{array}{l}\text { Electricity production } \\
\text { and distribution }\end{array}$ & 31 & Business services and real estate \\
\hline 6 & Leather goods & 19 & Gas distribution & 32 & Public administration and defence \\
\hline 7 & Wood and wood products & 20 & Water supply & 33 & Education \\
\hline 8 & Pulp paper and paperboard & 21 & Construction & 34 & Health, vetenary, social work \\
\hline 9 & $\begin{array}{l}\text { Coke ovens, refined petroleum } \\
\quad \& \text { nuclear fuel }\end{array}$ & 23 & Wholesale and retail distribution & 35 & Sewerage and sanitary services \\
\hline 10 & $\begin{array}{l}\text { Industrial products, fertilisers, } \\
\text { dyes, soaps, toiletries }\end{array}$ & 24 & Hotels and restaurants & 36 & Recreational and other services \\
\hline 11 & Rubber and plastic products & 25 & Railway transport & 37 & Private households \\
\hline 12 & Glass, ceramics, stone & 22 & Land transport & 38 & NPISH \\
\hline 13 & Metal products & 26 & Water transport & & \\
\hline
\end{tabular}

Derived from: (ONS 2012)

\section{References}

Acharya SN, Hazari BR (1971) Linkages and imports: a comparative study of India and Pakistan. J Dev Stud 8:107-115. doi:10.1080/00220387108421391

Alcántara V, Padilla E (2003) "Key" sectors in final energy consumption: an input-output application to the Spanish case. Energy Policy 31:1673-1678. doi:10.1016/S0301-4215(02)00233-1

Andergassen R, Nardini F, Ricottilli M (2015) Emergence and resilience in a model of innovation and network formation. Netw Spat Econ 15:293-311. doi:10.1007/s11067-014-9262-6

Andreosso-O'Callaghan B, Yue G (2004) Intersectoral linkages and key sectors in China, 1987-1997. Asian Econ J 18:165-183. doi:10.1111/j.1467-8381.2004.00188.x

Baer W, da Fonseca MAR, Guilhoto JJM (1987) Structural changes in Brazil's industrial economy, 19601980. World Dev 15:275-286. doi:10.1016/0305-750X(87)90082-9

Beyers WB (1976) Empirical identification of key sectors: some further evidence. Environ Plan A 8:231-236. doi:10.1068/a080231

Bottini N, Coelho M, Kao J (2012) Infrastructure and growth. London School of Economics. Available at: http://www. lse.ac.uk/researchAndExpertise/units/growthCommission/documents/pdf/SecretariatPapers/Infrastructure.pdf

Bulmer-Thomas V (1978) Trade, structure and linkages in Costa Rica: an input-output approach. J Dev Econ 5:73-86. doi:10.1016/0304-3878(78)90042-1

Cain LP (1997) Historical perspective on infrastructure and US economic development. Reg Sci Urban Econ 27:117-138. doi:10.1016/S0166-0462(96)02148-5

Caschili S, Medda FR, Wilson A (2015a) An interdependent multi-layer model: resilience of international networks. Netw Spat Econ 15:313-335. doi:10.1007/s11067-014-9274-2

Caschili S, Reggiani A, Medda F (2015b) Resilience and vulnerability of spatial economic networks. Netw Spat Econ. doi:10.1007/s11067-015-9283-9

Chakraborty C, Nandi B (2011) "Mainline" telecommunications infrastructure, levels of development and economic growth: evidence from a panel of developing countries. Telecommun Policy 35:441-449. doi: 10.1016/j.telpol.2011.03.004 
Chenery HB, Watanabe T (1958) International comparisons of the structure of production. Econometrica 26: 487-521. doi:10.2307/1907514

Clements BJ, Rossi JW (1991) Interindustry linkages and economics development: the case of Brazil reconsidered. Dev Econ 29:166-187. doi:10.1111/j.1746-1049.1991.tb00205.x

Crowther KG, Haimes YY (2010) Development of the multiregional inoperability input-output model (MRIIM) for spatial explicitness in preparedness of interdependent regions. Syst Eng 13:28-46

De Mesnard L (2007) About the Ghosh model: clarifications. LEG, Economy Series, Working Paper No. 2007-06. Available at SSRN: http://ssrn.com/abstract=1029614 or http://dx.doi.org/10.2139/ssrn.1029614

De Mesnard L (2009) Is the ghosh model interesting? J Reg Sci 49:361-372

Démurger S (2001) Infrastructure development and economic growth: an explanation for regional disparities in China? J Comp Econ 29:95-117. doi:10.1006/jcec.2000.1693

Diamond J (1974) The analysis of structural constraints in developing economies: a case study. Oxf Bull Econ Stat 36:95-108

Dietzenbacher E (1992) The measurement of interindustry linkages: key sectors in the Netherlands. Econ Model 9:419-437. doi:10.1016/0264-9993(92)90022-T

Dietzenbacher E (1997) In vindication of the ghosh model: a reinterpretation as a price model. J Reg Sci 37 : 629-651

Ghosh A (1958) Input-output approach in an allocation system. Economica 25:58-64. doi:10.2307/2550694

Guerra A-I, Sancho F (2011) Revisiting the original ghosh model: can it be made more plausible? Econ Syst Res 23:319-328

Haimes YY, Horowitz BM, Lambert JH et al (2005) Inoperability input-output model for interdependent infrastructure sectors. II: Case Stud J Infrastruct Syst 11:80-92. doi:10.1061/(ASCE)1076-0342(2005)11:2(80)

Haimes YY, Santos JR, Williams GM (2007) Assessing and managing the inoperability of transportation systems and interdependent sectors. Int J Risk Assess Manag 7:968-992. doi:10.1504/IJRAM.2007.014669

Hanly P (2012) Examining economic linkages between the Irish convention market and the rest of the economy: a close-knit relationship. J Convention Event Tour 13:159-180. doi:10.1080/15470148.2012.716746

Hazari BR (1970) Empirical identification of key sectors in the Indian economy. Rev Econ Stat 52:301-305. doi: $10.2307 / 1926298$

Hewings GJD (1982) The empirical identification of key sectors in an economy: a regional perspective. Dev Econ 20:173-195. doi:10.1111/j.1746-1049.1982.tb00444.x

Hirschman A (1958) The strategy of economic development. Yale University Press, New Haven

Jones L (1976) The measurement of hirschmanian linkages. Q J Econ 90:323-333. doi:10.2307/1884635

Jonkeren O, Azzini I, Galbusera L et al (2014) Analysis of critical infrastructure network failure in the European. A combined systems engineering and economic model. Networks and Spatial Economics, Union. doi:10.1007/s11067-014-9259-1

Kessides C (1993) The contributions of infrastructure to economic development: a review of experience and policy implications, 213th edn. World Bank Publications. HC79.C3K448

Laumas PS (1975) Key sectors in some underdeveloped countries. Kyklos 28:62-79. doi:10.1111/j.14676435.1975.tb01934.x

Lenzen M (2003) Environmentally important paths, linkages and key sectors in the Australian economy. Struct Chang Econ Dyn 14:1-34. doi:10.1016/S0954-349X(02)00025-5

Leontief WW (1951) The structure of American economy, 1919-1939 : an empirical application of equilibrium analysis. Oxford University Press, New York

Lian C, Santos JR, Haimes YY (2007) Extreme risk analysis of interdependent economic and infrastructure sectors. Risk Anal 27:1053-1064. doi:10.1111/j.1539-6924.2007.00943.x

Los B (2004) Identification of strategic industries: a dynamic perspective. Pap Reg Sci 83:669-698. doi:10. 1007/s10110-004-0221-3

Meller P, Marfán M (1981) Small and large industry: employment generation, linkages, and key sectors. Econ Dev Cult Chang 29:263-274

Miller RE, Blair PD (1985) Input-output analysis : foundations and extensions. Prentice-Hall, Englewood Cliffs

Miller RE, Blair PD (2009) Input-output analysis foundations and extensions. Cambridge University Press, Leiden

Miller RE, Temurshoev U (2013) Output upstreamness and input downstreamness of industries/countries in world production. Groningen Growth and Development Centre, University of Groningen

Miyazawa K (1966) Internal and external matrix multipliers in the input-output model. Hitotsubashi J Econ 7:38-55

Morrissey K, O’Donoghue C (2013) The role of the marine sector in the Irish national economy: an inputoutput analysis. Mar Policy 37:230-238. doi:10.1016/j.marpol.2012.05.004

New Scientist (2012) Last year costliest on record for natural disasters. New Scientist. doi: http://www. newscientist.com/article/mg21328474.200-last-year-costliest-on-record-for-natural-disasters.html 
O’Kelly ME (2015) Network hub structure and resilience. Netw Spat Econ 15:235-251. doi:10.1007/s11067014-9267-1

ONS (2009a) United Kingdom national accounts: the blue book. Palgrave Macmillan

ONS (2009b) United Kingdom balance of payments: the pink book. Palgrave Macmillan

ONS (2011) Release edition reference tables. In: Input-Output Analytical Tables, 2005 Edition. http://www. ons.gov.uk/ons/publications/re-reference-tables.html?edition=tcm\%3A77-237341. Accessed 11 Apr 2013

ONS (2012) Input-output archive data - ONS. In: Input Output Data Archive. http://www.ons.gov.uk/ons/guidemethod/method-quality/specific/economy/input-output/archive-data/index.html. Accessed 11 Oct 2013

Oosterhaven J (1988) On the plausibility of the supply-driven input-output model. J Reg Sci 28:203-217. doi: 10.1111/j.1467-9787.1988.tb01208.x

Oosterhaven J (1989) The supply driven input-output model: a new interpretation but still implausible. J Reg Sci 29:459-465. doi:10.1111/j.1467-9787.1989.tb01391.x

Oosterhaven J (1996) Leontief versus ghoshian price and quantity models. South Econ J 62:750-759. doi:10. $2307 / 1060892$

Oosterhaven J (2012) Adding supply-driven consumption makes the Ghosh model even more implausible. Econ Syst Res 24:101-111

Oosterhaven J, Stelder D (2002) On the economic impact of the transport sector: a critical review with Dutch bi-regional Input Output Data. In: Trade, networks and hierarchies: modeling regional and interregional economies. Springer, pp 119-133

Oosterhaven J, Piek G, Stelder D (1986) Theory and practice of updating regional versus interregional interindustry tables. Pap Reg Sci 59:57-72. doi:10.1111/j.1435-5597.1986.tb00982.x

Oosterhaven J, Eding GJ, Stelder D (2001) Clusters, linkages and interregional spillovers: methodology and policy implications for the two Dutch mainports and the rural North. Reg Stud 35:809-822. doi:10.1080/ 00343400120090239

Pradhan RP, Bagchi TP (2013) Effect of transportation infrastructure on economic growth in India: the VECM approach. Res Transp Econ 38:139-148. doi:10.1016/j.retrec.2012.05.008

Prud'Homme R (2004) Infrastructure and development. 28975. World Bank

Rasmussen PN (1956) Studies in inter-sectoral relations. PhD Thesis, E. Harck

Robles Teigeiro L, Sanjuán Solís J (2005) Key sectors: big coefficients and important coefficients in Spain. I Jornadas de Análisis Input-Output, Universidad de Oviedo, España, 2005, pp 22-23

Rose A, Allison T (1989) On the plausibility of the supply-driven input-output model: emperical evidence on joint stability. J Reg Sci 29:451

Schultz S (1977) Approaches to identifying key sectors empirically by means of input-output analysis. J Dev Stud 14:77-96. doi:10.1080/00220387708421663

Schultz S, Schumacher D (1976) Key sectors in some underdeveloped countries: a comment. Kyklos 29:765

Song Y, Liu C, Langston C (2006) Linkage measures of the construction sector using the hypothetical extraction method. Constr Manag Econ 24:579-589. doi:10.1080/01446190500435358

Sonis M, Hewings GJD (1992) Coefficient change in input-output models: theory and applications. Econ Syst Res 4:143-158. doi:10.1080/09535319200000013

Sonis M, Hewings GJD (1993) Hierarchies of regional sub-structures and their multipliers within input-output systems miyazawa revisited. Hitotsubashi J Econ 34:33-44

Stilwell LC, Minnitt RCA, Monson TD, Kuhn G (2000) An input-output analysis of the impact of mining on the South African economy. Resour Policy 26:17-30. doi:10.1016/S0301-4207(00)00013-1

Strassert G (1968) For the determination of strategic sectors using input - output models. Jahrb National Stat 182:211

Straub S (2008) Infrastructure and development: a critical appraisal of the macro level literature. WPS4590. World Bank

Temurshoev U (2010) Identifying optimal sector groupings with the hypothetical extraction method*. J Reg Sci 50:872-890. doi:10.1111/j.1467-9787.2010.00678.x

Temurshoev U, Oosterhaven J (2014) Analytical and empirical comparison of policy-relevant key sector measures. Spat Econ Anal 9:284-308. doi:10.1080/17421772.2014.930168

The Economist (2012) Natural disasters: counting the cost of calamities. Published: 14/01/2012. The Economist

Treasury HM (2013) National Infrastructure Plan 2013. https://www.gov.uk/government/publications/ national-infrastructure-plan-2013. Accessed 11 Jul 2014

Weber CL (2009) Measuring structural change and energy use: decomposition of the US economy from 1997 to 2002. Energy Policy 37:1561-1570. doi:10.1016/j.enpol.2008.12.027

Yotopoulos PA, Nugent JB (1973) A balanced-growth version of the linkage hypothesis: a test. Q J Econ 87: 157-171. doi:10.2307/1882181

Zhang P, Peeta S, Friesz T (2005) dynamic game theoretic model of multi-layer infrastructure networks. Netw Spat Econ 5:147-178. doi:10.1007/s11067-005-2627-0 